\title{
South African Dyslipidaemia Guideline Consensus Statement
}

\author{
A joint statement from the South African Heart Association (SA Heart) and the Lipid and \\ Atherosclerosis Society of Southern Africa (LASSA)
}

The European Society of Cardiology together with the European Atherosclerosis Society published updated dyslipidaemia guidelines in 2011. SA Heart and the Lipid and Atherosclerosis Society of Southern Africa officially adopt these guidelines. This statement adapts aspects of the guidelines to the South African situation. Using the updated Framingham risk charts, interventional strategies are based according to the cardiovascular risk score and low-density lipoprotein cholesterol (LDL-C) levels. The Framingham risk score refers to the 10-year risk of any cardiovascular event, and includes four categories of risk. Treatment targets are those of the European guidelines. The LDL-C goal is $1.8 \mathrm{mmol} / \mathrm{l}$ for the very high-risk group ( $>30 \%$ ), $2.5 \mathrm{mmol} / \mathrm{l}$ for the high-risk group (15 - 30\%), and $3 \mathrm{mmol} / \mathrm{l}$ for those below $15 \%$ risk. Intensive management of dyslipidaemia in South Africa will significantly reduce the cardiovascular disease health burden.

S Afr Med J 2012;102:177-188.

\section{Introduction}

In 2003, the South African Heart Association (SA Heart) and the Lipid and Atherosclerosis Society of Southern Africa (LASSA) officially adopted the European Guidelines for the Prevention of Cardiovascular Disease ${ }^{1}$ to replace the South African Lipid Guidelines published in 2000. ${ }^{2}$ The European document has recently been updated with the publication of the European Society of Cardiology (ESC)/European Society of Atherosclerosis (EAS) Guideline for the Management of Dyslipidaemias in 2011. ${ }^{3}$ This Consensus Statement promotes current best management of dyslipidaemia and should be adopted by all health care professionals in South Africa.

South Africa is a multi-ethnic society, with a large range of cultures and lifestyles at different stages of epidemiological transition. In all sub-populations, cardiovascular disease is a major cause of morbidity and mortality. Every day, approximately 80 people die of myocardial infarction or heart failure, while another 60 die due to stroke. ${ }^{4}$ The INTERHEART Africa study indicated that more premature acute myocardial infarctions occur in sub-Saharan Africa than in any other of the 52 countries participating in the INTERHEART study. ${ }^{5,6}$ This statistic reflects a lack of prevention, early detection and effective management of cardiovascular risk factors in the countries of this region. ${ }^{5}$ In particular, in the black population, with increasing urbanisation and adoption of an unhealthy lifestyle, the prevalence of CVD and the incidence of premature death are likely to continue to increase. ${ }^{4}$ Consequently, the timely institution of lifestyle modification, early diagnosis and effective management of CVD risk factors are essential to curb the epidemic of CVD that has been seen in other countries. ${ }^{5}$

Task Force: Chairman - Dr E Q Klug, MB BCh, MMed, FCP (SA), Members F J Raal, FCP (SA), FRCP, FRCPC, MMed, PhD, A D Marais, MB ChB, FCP (SA), M-R Taskinen, MD(Finland), AJDalby, MBChB,FCP(SA),FACC,CSchamroth, MB BCh, MMed, FCP (SA), FACC, N Rapeport, MB BCh, FCP (SA), FACP (Hon), D Jankelow, MB BCh, FCP (SA), D J Blom, MB ChB, MMed, FCP (SA), PhD, R Catsicas, RD (SA), D A Webb, BSc (Hons), MB BCh

\section{When to use the cardiovascular risk score \\ 2.1 Very high-risk individuals do not require risk scoring}

Individuals who are considered to be at very high risk of cardiovascular events are listed in Table 1. Patients in this group DO NOT require cardiovascular risk scoring, because the risk score will be an underestimate in these settings.

\subsection{Individuals who do not fall into the very high-risk category}

Risk scoring using well-documented key risk factors is appropriate to estimate the total cardiovascular risk in asymptomatic adults. Furthermore, risk scoring is especially important in individuals with the following:

- hypertension and/or on antihypertensive medication

- smoking: cigarette smoking is defined as any cigarette smoking

$\begin{array}{ll}\text { Abbreviations } & \\ \text { ACS } & \text { acute coronary syndromes } \\ \text { ALT } & \text { alanine aminotransferase } \\ \text { ARVs } & \text { antiretroviral drugs } \\ \text { BP } & \text { blood pressure } \\ \text { CHD } & \text { coronary heart disease } \\ \text { CK } & \text { creatine kinase } \\ \text { CVD } & \text { cardiovascular disease } \\ \text { GFR } & \text { glomerular filtration rate } \\ \text { HDL-C } & \text { high-density lipoprotein cholesterol } \\ \text { LDL-C } & \text { low-density lipoprotein cholesterol } \\ \text { hsCRP } & \text { high-sensitivity C-reactive protein } \\ \text { Lp(a) } & \text { lipoprotein (a) } \\ \text { MI } & \text { myocardial infarction } \\ \text { TC } & \text { total cholesterol } \\ \text { TG } & \text { triglyceride } \\ \text { TLC } & \text { therapeutic lifestyle change } \\ \text { ULN } & \text { upper limit of normal }\end{array}$


Table 1. Subjects considered to be at very high risk of cardiovascular events

- Established atherosclerotic disease, i.e.

- coronary artery disease

- cerebrovascular disease

- peripheral arterial disease

- Type 2 diabetes

- Type 1 diabetes with micro-albuminuria or proteinuria

- Genetic dyslipidaemia, e.g. familial hypercholesterolaemia

- Chronic kidney disease (GFR $<60 \mathrm{ml} / \mathrm{min} / 1.73 \mathrm{~m}^{2}$ )

in the past month or a history of 20 cigarettes per day for 10 years (10 pack years)

- $\quad$ BMI $\geq 30 \mathrm{~kg} / \mathrm{m}^{2}$ or waist circumference $>94 \mathrm{~cm}$ for men, $>80$ $\mathrm{cm}$ for women

- family history of premature CVD (male before 55 years of age, female before 60 years)

- auto-immune chronic inflammatory disease, e.g. rheumatoid arthritis, systemic lupus erythematosus, psoriasis.

\section{When to start screening}

In South Africa, because the prevalence of familial hypercholesterolaemia is as high as 1 in 100 in some communities, each individual should be tested, preferably with a full lipogram or at least TC/LDL-C, at least once in young adulthood (from 20 years of age). Particular attention should be paid to individuals with other risk factors for CVD.

\section{How to screen: using the Framingham Risk Score}

The European guidelines use the Systematic Coronary Risk Estimation (SCORE) system to estimate cardiovascular risk. Because this scoring system is based on an exclusively European population, it may not accurately reflect coronary risk in South Africa. While it is recognised that it would be impossible to accurately estimate risk in all South African subpopulations with a single data set, the Adult Treatment Panel (ATP) III Framingham risk tables, ${ }^{7}$ which provide an estimate of the 10-year risk of CHD, have been validated in white and black populations in the USA and are transportable to other culturally diverse populations. Consequently, we considered this approach to be more appropriate for South Africa. Nevertheless, these risk tables are likely to underestimate risk in South African black and Indian patients. The Framingham CHD tables may also underestimate total CVD risk in middle-aged and older women, whose risk of stroke and heart failure is typically higher than that of CHD. Even when multiple elevated risk factors are present, it is difficult for a woman younger than 75 years to exceed a $10 \%$ predicted risk for $\mathrm{CHD}$, precluding her from qualification for more aggressive CVD prevention. ${ }^{8}$ Consequently, more recent Framingham equations predict 10-year total CVD risk (including $\mathrm{CHD}$, stroke, transient ischaemic attack and heart failure) ${ }^{8,9}$

The updated Framingham CVD risk tables for men and women and an algorithm for management and cholesterol goals have been incorporated into these recommendations (Appendix 1).

\section{Measuring lipids}

\subsection{Low-density lipoprotein cholesterol}

LDL-C is preferred when deciding on treatment and assessing its effect. LDL-C is used in preference to other tests as it is modifiable by treatment and the beneficial effects of lowering LDL-C are known. LDL-C may be measured directly or calculated from the Friedewald equation (in mmol/l) (LDL-C = TC $-\mathrm{HDL}-\mathrm{C}-\mathrm{TG} / 2.2)$, provided the triglycerides do not exceed $4.5 \mathrm{mmol} / \mathrm{l}$.

\subsection{Total cholesterol}

Once the relationship between on-treatment TC and LDL-C is known, it may be appropriate to monitor TC only. TC may be used as an alternative for screening, risk assessment and monitoring of treatment efficacy if there are cost constraints or if there is difficulty in obtaining either direct or indirect LDL-C values.

Equivalent target values for TC are:

- $\mathrm{TC}=4.5 \mathrm{mmol} / \mathrm{l}$ is approximately equivalent to $\mathrm{LDL}-\mathrm{C}=2.5$ $\mathrm{mmol} / \mathrm{l}$

- $\mathrm{TC}=4.0 \mathrm{mmol} / \mathrm{l}$ is approximately equivalent to $\mathrm{LDL}-\mathrm{C}=1.8$ $\mathrm{mmol} / \mathrm{l}$.

If $\mathrm{TC}$ values remain uncontrolled and LDL-C measurement is unavailable, the patient should be referred to a specialist physician.

\subsection{Cost-effective testing}

A full lipogram (TC, HDL-C, LDL-C and triglycerides) is recommended for initial diagnosis of dyslipidaemia. In patients with pure hypercholesterolaemia, LDL-C alone is adequate for follow-up, but a full lipogram is recommended where increased LDL-C is not the only abnormality in the lipid profile. After initiating TLC alone, follow-up testing should be performed every 6 months. After initiating pharmacotherapy, changing the dose or changing the specific drug prescribed, testing should be repeated at $8( \pm 4)$ weeks and thereafter, once the patient is at goal, every 6 months.

\subsection{Point-of-care finger prick testing}

Various point-of-care tests are available. They provide various results, ranging from TC alone to a full lipogram. Where finger prick testing is performed, the facility should ensure that adequate quality controls are in place, that the test strips and devices are stored under appropriate conditions of temperature, humidity and light, and that precautions are taken to perform the test properly, with an adequate blood sample volume and without contamination. ${ }^{10}$ The finger should not be squeezed or 'milked', as this will give inaccurate results.

Finger prick testing is appropriate for screening and follow-up to determine where advice on lifestyle intervention is required (e.g. TC $>5 \mathrm{mmol} / \mathrm{l}$ ), but is not appropriate to commit a patient to a lifetime of therapy. Where a screening finger prick TC measurement is high ( $>5 \mathrm{mmol} / \mathrm{l}$ ), the patient should be encouraged to discuss their finger prick screening result with their doctor, who should have a full laboratory-performed fasting lipogram done and then perform a full cardiovascular risk assessment. Because inappropriately low results are a concern, TC $<2.5 \mathrm{mmol} / \mathrm{l}$ on a finger prick test should be confirmed. Finger prick testing that measures TC alone will not detect raised triglycerides.

\subsection{Additional testing}

The use of novel biomarkers of CVD (e.g. hsCRP) and imaging technologies (e.g. coronary calcium scoring, carotid intima-media thickness) is not recommended routinely and should be reserved to refine risk assessment in patients considered to be at moderate risk where there is uncertainty about whether to initiate drug therapy. ${ }^{8}$ It should be noted that hsCRP is a nonspecific inflammatory marker that may be elevated from many causes (e.g. acute infections or non-infectious inflammatory disorders). Measuring $L p(a)$ is only appropriate in HIGH CVD risk subjects and/or when there is a family 
history of premature CVD. When $\operatorname{Lp}(\mathrm{a})$ is used as a risk marker, the cut-off value is $>50 \mathrm{mg} / \mathrm{dl}$.

\subsection{Secondary dyslipidaemias}

Dyslipidaemia may occur in response to another condition or treatment. Table 2 lists those encountered most commonly. The appropriate diagnostic tests should be performed when secondary dyslipidaemia is suspected and the underlying abnormality treated.

\section{Strategy for intervention}

The risk levels determined for the SCORE system refer to the 10-year risk of a fatal CVD event, whereas the Framingham scoring system refers to the 10-year risk of any CVD event. Risk thresholds for the Framingham score are therefore approximately 3 times those for SCORE.

Table 3 sets out the recommended appropriate intervention strategies according to the percentage risk calculated from the Framingham risk score and the LDL-C value obtained.

\section{Treatment targets}

Although we recommend the use of the Framingham risk charts to estimate cardiovascular risk, the management of patients, once risk has been determined, and the goals of therapy, are those of the European guidelines.

\section{Table 2. Secondary causes of dyslipidaemia}

Diabetes mellitus
Hypothyroidism
Liver disease
Renal disease, e.g. nephrotic
Alcohol excess
Medications:
- progestins
- steroids
- antiretroviral agents
- retinoids

Table 3. Intervention strategies as a function of Framingham total CVD risk score and LDL-C levels ${ }^{3 *}$

\begin{tabular}{|c|c|c|c|c|}
\hline \multirow{2}{*}{ Total CVD risk score ${ }^{\dagger}$} & \multicolumn{4}{|c|}{ LDL-C levels } \\
\hline & $<1.8 \mathrm{mmol} / \mathrm{l}$ & $1.8-<2.5 \mathrm{mmol} / \mathrm{l}$ & $2.5-4.9 \mathrm{mmol} / \mathrm{l}$ & $>4.9 \mathrm{mmol} / \mathrm{l}$ \\
\hline $\begin{array}{l}<3 \% \\
\text { Low risk }\end{array}$ & No lipid intervention & No lipid intervention & Lifestyle intervention & $\begin{array}{l}\text { Lifestyle intervention, } \\
\text { consider drug if } \\
\text { uncontrolled }\end{array}$ \\
\hline $\begin{array}{l}3-15 \% \\
\text { Moderate risk }\end{array}$ & Lifestyle intervention & Lifestyle intervention & $\begin{array}{l}\text { Lifestyle intervention, } \\
\text { consider drug if } \\
\text { uncontrolled }\end{array}$ & $\begin{array}{l}\text { Lifestyle intervention, } \\
\text { consider drug if } \\
\text { uncontrolled }\end{array}$ \\
\hline $\begin{array}{l}15-30 \% \\
\text { High risk }\end{array}$ & $\begin{array}{l}\text { Lifestyle intervention, } \\
\text { consider drug }{ }^{\ddagger}\end{array}$ & $\begin{array}{l}\text { Lifestyle intervention, } \\
\text { consider drug } \ddagger\end{array}$ & $\begin{array}{l}\text { Lifestyle intervention } \\
\text { and immediate drug } \\
\text { intervention }\end{array}$ & $\begin{array}{l}\text { Lifestyle intervention } \\
\text { and immediate drug } \\
\text { intervention }\end{array}$ \\
\hline $\begin{array}{l}>30 \% \\
\text { Very high risk }\end{array}$ & $\begin{array}{l}\text { Lifestyle intervention, } \\
\text { consider drug } \ddagger\end{array}$ & $\begin{array}{l}\text { Lifestyle intervention } \\
\text { and immediate drug } \\
\text { intervention }\end{array}$ & $\begin{array}{l}\text { Lifestyle intervention } \\
\text { and immediate drug } \\
\text { intervention }\end{array}$ & $\begin{array}{l}\text { Lifestyle intervention } \\
\text { and immediate drug } \\
\text { intervention }\end{array}$ \\
\hline
\end{tabular}

LDL-C goals for patients at different levels of Framingham risk are

\section{Management of dyslipidaemia}

Because the total cardiovascular risk is the product of a number of risk factors, the treatment of dyslipidaemia must always be seen within the broader framework of cardiovascular disease prevention.

\subsection{Lifestyle modification}

It should be emphasised that the cornerstone of any programme to reduce cardiovascular risk is TLC (healthy diet, regular exercise). In order for the changes to be sustainable, dietary and exercise advice must be practical and tailored specifically to the individual's personal and cultural preferences. ${ }^{11}$ Diets may need to be modified for people with unusual or specific disorders (e.g. hypertriglyceridaemia) and referral to a dietician and fitness professional is encouraged. An example of lifestyle and dietary advice that is relevant to the South African population is listed in Appendix 2.

\subsection{Dietary supplements}

Epidemiological and interventional studies support the role of healthy dietary choices as a whole to help reduce the risk of cardiovascular events. However, insufficient evidence exists to recommend the use of dietary supplements in patients with dyslipidaemia. While some dietary supplements have been shown to influence plasma lipids, there are no outcomes data that show benefits with regard to CVD prevention. Conversely, there is evidence that some supplements may be harmful to health and may interact with prescription medicines. ${ }^{12,13}$ Consumers should be advised to beware of unsubstantiated advertising claims relating to long-term health benefits.

Although there are no known risks associated with its use, the routine use of coenzyme Q10 to reduce statin-related myalgia or myopathy is not supported by systematic reviews of the medical literature. ${ }^{14,15}$

\subsection{Statin therapy}

Statins have demonstrated effectiveness in both primary and secondary prevention. The effect is dependent on the extent to which LDL-C is lowered and not on the type of statin used. At their listed in Table 4. 
Table 4. LDL-C treatment targets

\begin{tabular}{|l|l|l|}
\hline Total Framingham CVD risk (\%) & ESC/EAS risk classification & ESC/EAS LDL-C target \\
\hline$<3$ & Low risk & $<3.0 \mathrm{mmol} / \mathrm{l}$ \\
\hline $3-15$ & Moderate risk & $<3.0 \mathrm{mmol} / \mathrm{l}$ \\
\hline $15-30$ & High risk & $<2.5 \mathrm{mmol} / \mathrm{l}$ \\
\hline$>30$ & Very high risk & $<1.8 \mathrm{mmol} / \mathrm{l}$ \\
\hline
\end{tabular}

maximum doses, the various statins differ in their capacity to lower LDL-C.

For every $\mathrm{mmol} / \mathrm{l}$ reduction in LDL-C there is a:

- $10 \%$ reduction in mortality

- $20 \%$ reduction in all-cause morbidity

- $23 \%$ reduction in major cardiac events

- $17 \%$ reduction in stroke.

The effect of statin therapy is similar in all patient subgroups and becomes significant after 1 year, increasing progressively thereafter.

\subsection{High-dose simvastatin treatment}

Although the incidence of myopathy is very low for all the statins, it is approximately 3 times as high with $80 \mathrm{mg}$ simvastatin compared with maximum doses of atorvastatin and rosuvastatin. Accordingly, the American Food and Drug Administration (FDA) has mandated safety-labelling changes for medicines containing simvastatin, which include the following recommendations: $:^{16}$

- The use of $80 \mathrm{mg}$ simvastatin should be restricted to those who have been using the dose chronically (longer than 12 months), without signs or symptoms of myopathy.

- Patients who are using simvastatin $80 \mathrm{mg}$ and who need to start taking another drug that may interact with simvastatin should be switched to an alternative statin with a lower risk of drug interactions, such as rosuvastatin or atorvastatin.

- Patients who do not reach their LDL-C goal with $40 \mathrm{mg}$ simvastatin should be switched to an appropriate alternative more potent statin with a lower potential for myopathy.

- To reduce the incidence of myopathy:

- do not exceed $10 \mathrm{mg}$ simvastatin with amiodarone, verapamil, or diltiazem

- do not exceed $20 \mathrm{mg}$ simvastatin with amlodipine

- simvastatin is contraindicated with azole antifungals, macrolide antibiotics, HIV protease inhibitors, gemfibrozil, cyclosporine and danazol.

\subsection{Statin toxicity}

When used in appropriate patients, statins are remarkably safe drugs and the benefits of cardiovascular protection far outweigh the potential for toxicity. However, patients should be encouraged to make and sustain healthy lifestyle choices and the lowest dose of statin to achieve LDL-C target should be used.

\subsubsection{Statin-related myalgia and rhabdomyolysis}

The presence of any musculoskeletal pain should be documented before starting statin therapy to facilitate the recognition of statininduced myalgia during treatment.

A CK measurement prior to commencing statin treatment is recommended. Statins should not be started if the CK is $>5$ times the ULN. Routine CK monitoring is not necessary during treatment, unless the patient develops myalgia. Increased vigilance regarding $\mathrm{CK}$ and myopathy is necessary in the elderly, in those on concomitant interfering treatment or on multiple medications, and in the presence of liver or renal disease.

If myalgia develops and the CK is $>5$ times the ULN:

- $\quad$ stop treatment

- check renal function

- monitor CK every 2 weeks

- consider causes of transient CK elevation, e.g. exercise

- consider alternative causes of myopathy.

If myalgia develops and the CK is $<5$ times the ULN:

- monitor symptoms

- monitor CK regularly.

If the CK is $<5$ times the ULN and there are no muscle symptoms:

- continue statin

- $\quad$ alert patient to report symptoms

- consider monitoring CK.

The incidence of rhabdomyolysis is very low.

In patients who are intolerant to statin therapy, potent statins, such as atorvastatin or rosuvastatin, may be used on alternate days (e.g. Monday, Wednesday, Friday) or even less frequently to reduce sideeffects. ${ }^{17}$ Alternatively, a combination therapy of a low-dose statin with a lipid-lowering drug of another class (e.g. ezetimibe) can be considered.

\subsubsection{Statin-induced rises in alanine aminotransferase}

Baseline ALT measurement should be performed before initiating treatment with a statin. If the ALT is normal, it does not need to be repeated. Raised ALT does not exclude statin therapy, where treatment should be individualised. Alternative reasons for raised ALT (e.g. haemochromatosis, fatty liver) should be investigated where necessary.

If the ALT is raised $<3$ times the ULN while on treatment, continue the statin and recheck ALT in $4-6$ weeks. If the ALT is raised $>3$ times the ULN on treatment, stop the statin and repeat ALT in $4-6$ weeks. Cautious reintroduction of the statin can be considered once the ALT has returned to normal.

\subsubsection{New-onset diabetes}

Recent meta-analyses have demonstrated a very small increase in the risk of new-onset diabetes associated with statin use, notably in patients treated with intensive-dose statin therapy and in older patients. ${ }^{18,19}$ However, this small potential adverse risk is outweighed by the absolute reduction in CV events and should not discourage initiation of statin therapy. ${ }^{3,19,20}$

\subsection{Scheme for introducing statin treatment}

- First evaluate the risk.

- Involve the patient in CV risk management decisions.

- Identify the appropriate LDL-C target.

- Calculate \% reduction in LDL-C required to reach target.

- Choose the statin (and dose) able to achieve the desired reduction (Table 5). 


\section{GUIDELINE}

Table 5. Practical guide to initiating statins depending on baseline LDL-C and target LDL-C values ${ }^{*}$

\begin{tabular}{|c|c|c|c|c|c|c|}
\hline \multirow[b]{2}{*}{$\begin{array}{l}\text { Starting LDL-C } \\
(\mathrm{mmol})\end{array}$} & \multicolumn{2}{|c|}{ Goal: $<1.8 \mathrm{mmol} / \mathrm{l}$} & \multicolumn{2}{|c|}{ Goal: $<2.5 \mathrm{mmol} / \mathrm{l}$} & \multicolumn{2}{|c|}{ Goal: $<3.0 \mathrm{mmol} / \mathrm{l}$} \\
\hline & $\begin{array}{l}\% \text { reduction } \\
\text { required }\end{array}$ & Statin dose & $\begin{array}{l}\% \text { reduction } \\
\text { required }\end{array}$ & Statin dose & $\begin{array}{l}\% \text { reduction } \\
\text { required }\end{array}$ & Statin dose \\
\hline$>6.2$ & $>70^{\dagger}$ & $\begin{array}{l}\text { Rosuvastatin } 40 \mathrm{mg} \\
\text { Atorvastatin } 80 \mathrm{mg}\end{array}$ & $>60^{\dagger}$ & $\begin{array}{l}\text { Rosuvastatin } 40 \mathrm{mg} \\
\text { Atorvastatin } 80 \mathrm{mg}\end{array}$ & $>55$ & $\begin{array}{l}\text { Rosuvastatin } 40 \mathrm{mg} \\
\text { Atorvastatin } 80 \mathrm{mg}\end{array}$ \\
\hline $5.2-6.2$ & $65-70^{\dagger}$ & $\begin{array}{l}\text { Rosuvastatin } 40 \mathrm{mg} \\
\text { Atorvastatin } 80 \mathrm{mg}\end{array}$ & $50-60$ & $\begin{array}{l}\text { Rosuvastatin } 20 \mathrm{mg} \\
\text { Atorvastatin } 40 \mathrm{mg}\end{array}$ & $40-55$ & $\begin{array}{l}\text { Rosuvastatin } 10 \mathrm{mg} \\
\text { Atorvastatin } 20 \mathrm{mg}\end{array}$ \\
\hline $4.4-5.2$ & $60-65^{\dagger}$ & $\begin{array}{l}\text { Rosuvastatin } 40 \mathrm{mg} \\
\text { Atorvastatin } 80 \mathrm{mg}\end{array}$ & $40-50$ & $\begin{array}{l}\text { Rosuvastatin } 10 \mathrm{mg} \\
\text { Atorvastatin } 20 \mathrm{mg} \\
\text { Simvastatin } 40 \mathrm{mg}\end{array}$ & $30-45$ & $\begin{array}{l}\text { Rosuvastatin } 5 \mathrm{mg} \\
\text { Atorvastatin } 10 \mathrm{mg} \\
\text { Simvastatin } 20 \mathrm{mg} \\
\text { Lovastatin } 40 \mathrm{mg} \\
\text { Fluvastatin } 80 \mathrm{mg}\end{array}$ \\
\hline $3.9-4.4$ & $55-60$ & $\begin{array}{l}\text { Rosuvastatin } 40 \mathrm{mg} \\
\text { Atorvastatin } 80 \mathrm{mg}\end{array}$ & $35-40$ & $\begin{array}{l}\text { Rosuvastatin } 5 \mathrm{mg} \\
\text { Atorvastatin } 10 \mathrm{mg} \\
\text { Simvastatin } 20 \mathrm{mg} \\
\text { Lovastatin } 40 \mathrm{mg} \\
\text { Fluvastatin } 80 \mathrm{mg}\end{array}$ & $25-30$ & $\begin{array}{l}\text { Rosuvastatin } 5 \mathrm{mg} \\
\text { Atorvastatin } 10 \mathrm{mg} \\
\text { Simvastatin } 10 \mathrm{mg} \\
\text { Lovastatin } 20 \mathrm{mg} \\
\text { Pravastatin } 40 \mathrm{mg} \\
\text { Fluvastatin } 80 \mathrm{mg}\end{array}$ \\
\hline $3.4-3.9$ & $45-55$ & $\begin{array}{l}\text { Rosuvastatin } 10 \mathrm{mg} \\
\text { Atorvastatin } 40 \mathrm{mg}\end{array}$ & $25-35$ & $\begin{array}{l}\text { Rosuvastatin } 5 \mathrm{mg} \\
\text { Atorvastatin } 10 \mathrm{mg} \\
\text { Simvastatin } 10 \mathrm{mg} \\
\text { Lovastatin } 20 \mathrm{mg} \\
\text { Pravastatin } 40 \mathrm{mg} \\
\text { Fluvastatin } 80 \mathrm{mg}\end{array}$ & $10-25$ & $\begin{array}{l}\text { Any statin at lowest } \\
\text { dose }\end{array}$ \\
\hline $2.9-3.4$ & $35-45$ & $\begin{array}{l}\text { Rosuvastatin } 5 \mathrm{mg} \\
\text { Atorvastatin } 10 \mathrm{mg} \\
\text { Simvastatin } 20 \mathrm{mg} \\
\text { Lovastatin } 40 \mathrm{mg} \\
\text { Fluvastatin } 80 \mathrm{mg}\end{array}$ & $10-25$ & $\begin{array}{l}\text { Any statin at lowest } \\
\text { dose }\end{array}$ & $<10$ & $\begin{array}{l}\text { Any statin at lowest } \\
\text { dose }\end{array}$ \\
\hline $2.3-2.9$ & $22-35$ & $\begin{array}{l}\text { Rosuvastatin } 5 \mathrm{mg} \\
\text { Atorvastatin } 10 \mathrm{mg} \\
\text { Simvastatin } 10 \mathrm{mg} \\
\text { Lovastatin } 10 \mathrm{mg} \\
\text { Pravastatin } 20 \mathrm{mg} \\
\text { Fluvastatin } 40 \mathrm{mg}\end{array}$ & $<10$ & $\begin{array}{l}\text { Any statin at lowest } \\
\text { dose }\end{array}$ & - & \\
\hline $1.8-2.3$ & $<22$ & $\begin{array}{l}\text { Rosuvastatin } 5 \mathrm{mg} \\
\text { Atorvastatin } 10 \mathrm{mg} \\
\text { Simvastatin } 10 \mathrm{mg} \\
\text { Lovastatin } 10 \mathrm{mg} \\
\text { Pravastatin } 20 \mathrm{mg} \\
\text { Fluvastatin } 40 \mathrm{mg}\end{array}$ & - & & - & \\
\hline
\end{tabular}

*Based on weighted average of pooled analysis at starting dose. Dose should be titrated according to response.

$\dagger$ Maximum LDL-C reduction achievable with high-dose statin monotherapy is $50-60 \%$. To achieve a reduction in LDL-C of $>60 \%$, another cholesterol-lowering agent in addition to statin therapy may be required.

Adapted from Reiner Ž, et al., Eur Heart J 2011;32:1769-1818 ${ }^{3}$ and Weng T-C, et al., J Clin Pharm Ther 2010;35:139-151. ${ }^{21}$ 


\subsection{Treatment directed at other components of the lipid profile}

Whereas low levels of HDL-C and high levels of TG are undoubtedly associated with a higher cardiovascular disease risk, no currently available treatment directed at reversing these changes has been shown to significantly benefit cardiovascular outcome.

A high triglyceride level, particularly if $>10 \mathrm{mmol} / \mathrm{l}$, can result in acute pancreatitis and should be treated without delay.

\section{Special circumstances 9.1 Metabolic syndrome}

The European Guidelines recognise the importance of identifying patients with the metabolic syndrome, who are at increased risk of cardiovascular disease. The presence of the syndrome approximately doubles the risk of cardiovascular disease. Lifestyle changes, particularly reducing body weight and increasing physical activity, are the cornerstone of management of the metabolic syndrome..$^{23}$

\subsection{Acute coronary syndromes}

A lipid profile should be obtained at the time of admission in patients presenting with ACS. They should be treated with high-dose statin therapy during their acute care and the statin dose should be adjusted at the time of discharge according to the admission lipid profile.

\subsection{HIV infection}

Dyslipidaemia frequently accompanies HIV and may be aggravated by ARVs. While there is limited information, particularly in South Africa, it is important to measure lipids in patients with HIV and estimate their CVD risk, and a full lipogram should be performed before initiating ARV treatment. The Framingham tables will generally underestimate CVD risk in this population. In patients with high lipid levels already on ARV treatment, switching to an alternative ARV and cautious use of a statin or fibrate as necessary should be considered. Simvastatin is contraindicated in patients using protease inhibitors.

\subsection{Unusual conditions}

Unexplained cutaneous or tendinous deposits (xanthomata), very premature vascular disease, some endocrine, metabolic and neurological disorders constitute reasons for referral. Unusually low TC $(<2.5 \mathrm{mmol} / \mathrm{l})$, LDL-C $(<1.5 \mathrm{mmol} / \mathrm{l})$, HDL-C $(<0.7 \mathrm{mmol} / \mathrm{l})$ or unusually high TG $(>10 \mathrm{mmol} / \mathrm{l})$, TC $(>15 \mathrm{mmol} / \mathrm{l})$, LDL-C $(>12$ $\mathrm{mmol} / \mathrm{l})$, HDL-C (>2.5 $\mathrm{mmol} / \mathrm{l})$ also deserve special consideration.

\section{Conclusions: implementation of the 2011 guidelines}

In order to implement the guidelines, we propose a simple chart that has been updated to accommodate the new Framingham CVD risk tables (Appendix 1). The chart is a guide to management only and should not replace an individualised assessment and treatment plan based on the clinical judgement of the doctor. We encourage the reader to read the 2011 European guidelines in full, which may be accessed on the ESC website www.escardio.org/guidelines. We hope that dissemination of these guidelines will go some way towards helping to reduce the burden of CVD in South Africa.

\section{Mechanism of guideline preparation}

In October 2011 a broad-based group of participants from the medical and allied health community, medical funders, pharmaceutical companies, the Department of Health, the Board of Health Funders and the Heart and Stroke Foundation met together with Professor
Marja-Riitta Taskinen in Sandton, Johannesburg, to examine and discuss the joint ESC/EAS dyslipidaemia guidelines. Professor Taskinen is a co-author and Task Force Member of these guidelines and attended on behalf of the European Atherosclerosis Society.

The following day a writing committee met to construct the South African Consensus Document.

Additional delegates attending the Dyslipidaemia Guidelines Meeting Discussion Group were Dr A Amod (SEMDSA), Ms G Bartlett (Universal Health), Ms U Behrtel, Dr S Bhana (Netactive), Ms M Campbell (Discovery), Mr D Craythorne (Cipla), Mr A Dansay (PharmaDynamics), Ms L Doms (Medscheme), Ms A du Plessis (Vital Health), Ms U du Preez (Astra Zeneca), Dr R Espaillat (Abbott Laboratories), Dr Craige Golding (Solal Laboratories), Ms K Jamaloodien (National Department of Health), Dr D Katzman (MSD), Dr S Kahn, Mr M Lambert (Aspen), Dr M Makotoko, Mr M Mashego (Adcock Ingram), Ms Y Misra (MediKredit), Dr M Mpe, Dr V Mungai-Singh (Heart and Stroke Foundation), Ms L Naidoo (Sanlam Healthcare), Ms N Nel, Dr R Patel (Board of Healthcare Funders), Ms D Pithey (MSD), Mr J Rall (Ranbaxy), Dr J Snyman (Agility Global Health Solutions), Dr M Sussman (SA Heart), Dr M Swanepoel (Medihelp), Professor J P van Niekerk (South African Medical Journal), Ms L Xiphu (QUALSA/Metropolitan).

\section{References}

1. De Backer G, Ambrosioni E, Borch-Johnson K, et al. European guidelines on cardiovascular disease prevention in clinical practice. Eur Heart J 2003:24:1601-1610.

2. South African Medical Association and Lipid and Atherosclerosis Society of Southern Africa Working Group. Diagnosis, management and prevention of the common dyslipidaemias in South Africa Clinical Guideline, 2000.S Afr Med J 2000:90:164-178.

3. Reiner $\check{Z}$, Catapano AL, De Backer G, et al, for the Task Force for the management of dyslipidaemias of the European Society for Cardiology (ESC) and the European Atherosclerosis Society (EAS). ESC/EAS guidelines for the management of dyslipidaemias. Eur Heart J 2011;32:1769-1818.

4. Steyn K. Heart disease in South Africa. Media data document. Heart and Stroke Foundation South Africa, July 2007.

Steyn K, Sliwa K, Hawken S, et al. Risk factors associated with myocardial infarction in Africa. The INTERHEART Africa Study. Circulation 2005;112:3554-3561.

6. Yusuf S, Hawken S, Ônpuu S. Effect of potentially modifiable risk factors associated with myocardial infarction in 52 countries (the INTERHEART study): case-control study. Lancet 2004;364(9438):937952.

7. National Institutes of Health, National Heart, Lung \& Blood Institute. Third Report of the Nationa CholesterolEducation Program (NCEP) Expert Panel on Detection, Evaluation and Treatment of High Chod Cho (10.3670,

8. Mosca L Benjamin EJ, Berra $\mathrm{K}$, et al. Effectiveness-based guidelines for the prevention of cardiovascular disease in women 2011 update: A guideline from the American Heart Association. Circulation 2011;123:1243-126

9. D’Agostino RB, Vasan RS, Pencina MJ, et al. General cardiovascular risk profile for use in primary care the Framingham Heart Study. Circulation 2008;117:743-753.

10. Batki AD, Nayyar P, Thomason HL. Buyer's guide: Point-of-care testing for cholesterol measurement. NHS Purchasing and Supply Agency. Center for Evidence-based Purchasing. CEP 09020; September 2009. http://www.healthcheck.nhs.uk/Library/pointofcare_testing_for_cholesterol_measurement.pd (accessed 26 October 2011).

1. Sacks F, Bray GA, Carey VJ, et al. Comparison of weight-loss diets with different compositions of fat, protein, and carbohydrates. N Engl J Med 2009;360(9):859-873.

2. Violi F, Pignatelli P, Basili S. et al. Nutrition, supplements and vitamins in platelet functions and bleeding. Circulation 2010;121:1033-1044.

13. Mursu J, Robien K, Harnack LJ, et al. Dietary supplements and mortality rate in older women. The IOWA Women's Health Study. Arch Intern Med 2011;171(18):1625-1633.

14. Marcoff L, Thompson PD. The role of coenzyme Q10 in statin-associated myopathy. A systematic review. J Am Coll Cardiol 2007;49(23):2231-2237.

15. Schaars CF, Stalenhoef AFH. Effects of ubiquinone (coenzyme Q10) on myopathy in statin users. Cur Opin Lipidol 2008; 19:553-557.

16. Egan A, Coleman E. Weighing the benefits of high-dose simvastatin against the risk of myopathy. N Engl J Med 2011;365(4):285-287.

7. Eckel RH. Approach to the patient who is intolerant of statin therapy. J Clin Endocrinol Metab 2010;95(5):2015-2022.

18. Preiss D, Seshasai SRK, Welsh P, et al. Risk of incident diabetes with intensive-dose compared with moderate-dose statin therapy. JAMA 2011;305(24):2556-2564.

9. Sattar N, Preiss D, Murray HM, et al. Statins and risk of incident diabetes: a collaborative meta-analysis of randomised statin trials. Lancet 2010;375(9716):735-742.

20. Rajpathak SN, Kumbhani DJ, Crandall J, et al. Statin therapy and risk of developing type 2 diabetes: A meta-analysis. Diab Care 2009;32:1924-1929.

21. Weng T-C, Kao Yang Y-H, Lin S-J, et al. A systematic review and meta-analysis on the therapeutic equivalence of statins. J Clin Pharm Ther 2010;35:139-151.

22. Baigent C, Landray MJ, Reith C, et al. The effects of lowering LDL cholesterol with simvastatin plus ezetimibe in patients with chronic kidney disease (Study of Heart and Renal Protection): a randomised placebo controlled trial. Lancet 2011;377:2181-2181.

23. Alberti KGMM, Eckel RH, Grundy SM, et al. Harmonizing the metabolic syndrome. A joint interim statement of the International Diabetes Federation Task Force on Epidemiology and Prevention National Heart, Lung, and Blood Institute; American Heart Association; World Heart Federation International Atherosclerosis Society; and International Association for the Study of Obesity. Circulation 2009;120:1640-164 
Appendix 1. Cardiovascular risk stratification

Framingham 10-year risk assessment chart for patients without diabetes

Risk of CVD: coronary heart disease, stroke, peripheral artery disease, or heart failure

\begin{tabular}{|} 
Estimate of 10-year risk of CVD for men \\
\begin{tabular}{|c|c|}
\hline Age (yrs) & Points \\
\hline $30-34$ & 0 \\
\hline $35-39$ & 2 \\
\hline $40-44$ & 5 \\
\hline $45-49$ & 6 \\
\hline $50-54$ & 8 \\
\hline $55-59$ & 10 \\
\hline $60-64$ & 11 \\
\hline $65-69$ & 12 \\
\hline $70-74$ & 14 \\
\hline 75 years or older & 15 \\
\hline
\end{tabular}
\end{tabular}

\begin{tabular}{|} 
Estimate of 10-year risk of CVD for women \\
\begin{tabular}{|c|c|}
\hline Age (yrs) & Points \\
\hline $30-34$ & 0 \\
\hline $35-39$ & 2 \\
\hline $40-44$ & 4 \\
\hline $45-49$ & 5 \\
\hline $50-54$ & 7 \\
\hline $55-59$ & 8 \\
\hline $60-64$ & 9 \\
\hline $65-69$ & 10 \\
\hline $70-74$ & 11 \\
\hline 75 years or older & 12 \\
\hline
\end{tabular}
\end{tabular}

\begin{tabular}{|c|c|}
\hline Total cholesterol (mmol/l) & Points \\
\hline$<4.10$ & 0 \\
\hline $4.10-5.19$ & 1 \\
\hline $5.2-6.19$ & 2 \\
\hline $6.20-7.20$ & 3 \\
\hline$>7.20$ & 4 \\
\hline
\end{tabular}

\begin{tabular}{|c|c|}
\hline Total cholesterol $(\mathbf{m m o l} / \mathbf{l})$ & Points \\
\hline$<4.10$ & 0 \\
\hline $4.10-5.19$ & 1 \\
\hline $5.2-6.19$ & 3 \\
\hline $6.20-7.20$ & 4 \\
\hline$>7.20$ & 5 \\
\hline
\end{tabular}

\begin{tabular}{|c|c|}
\hline HDL-cholesterol (mmol/l) & Points \\
\hline$\geq 1.50$ & -2 \\
\hline $1.30-1.49$ & -1 \\
\hline $1.20-1.29$ & 0 \\
\hline $0.90-1.19$ & 1 \\
\hline$<0.90$ & 2 \\
\hline
\end{tabular}

\begin{tabular}{|c|c|}
\hline HDL-cholesterol (mmol/l) & Points \\
\hline$\geq 1.50$ & -2 \\
\hline $1.30-1.49$ & -1 \\
\hline $1.20-1.29$ & 0 \\
\hline $0.90-1.19$ & 1 \\
\hline$<0.90$ & 2 \\
\hline
\end{tabular}

\begin{tabular}{|c|c|}
\hline Systolic BP - untreated (mmHg) & Points \\
\hline$<120$ & -2 \\
\hline $120-129$ & 0 \\
\hline $130-139$ & 1 \\
\hline $140-159$ & 2 \\
\hline$\geq 160$ & 3 \\
\hline
\end{tabular}

\begin{tabular}{|c|c|}
\hline Systolic BP - untreated $(\mathbf{m m H g})$ & Points \\
\hline$<120$ & -3 \\
\hline $120-129$ & 0 \\
\hline $130-139$ & 1 \\
\hline $140-149$ & 2 \\
\hline $150-159$ & 4 \\
\hline$\geq 160$ & 5 \\
\hline
\end{tabular}

\begin{tabular}{|c|c|}
\hline $\begin{array}{c}\text { Systolic BP - on } \\
\text { antihypertensive treatment } \\
(\mathbf{m m H g})\end{array}$ & Points \\
\hline$<120$ & 0 \\
\hline $120-129$ & 2 \\
\hline $130-139$ & 3 \\
\hline $140-159$ & 4 \\
\hline$\geq 160$ & \\
\hline & Points \\
\hline Smoker & 0 \\
\hline No & 4 \\
\hline Yes & \\
\hline
\end{tabular}

\begin{tabular}{|c|c|}
\hline $\begin{array}{c}\text { Systolic BP - on } \\
\text { antihypertensive treatment } \\
(\mathbf{m m H g})\end{array}$ & Points \\
\hline$<120$ & -1 \\
\hline $120-129$ & 2 \\
\hline $130-139$ & 3 \\
\hline $140-149$ & 5 \\
\hline $150-159$ & 6 \\
\hline$\geq 160$ & 7 \\
\hline Smoker & Points \\
\hline No & 0 \\
\hline Yes & 3 \\
\hline
\end{tabular}




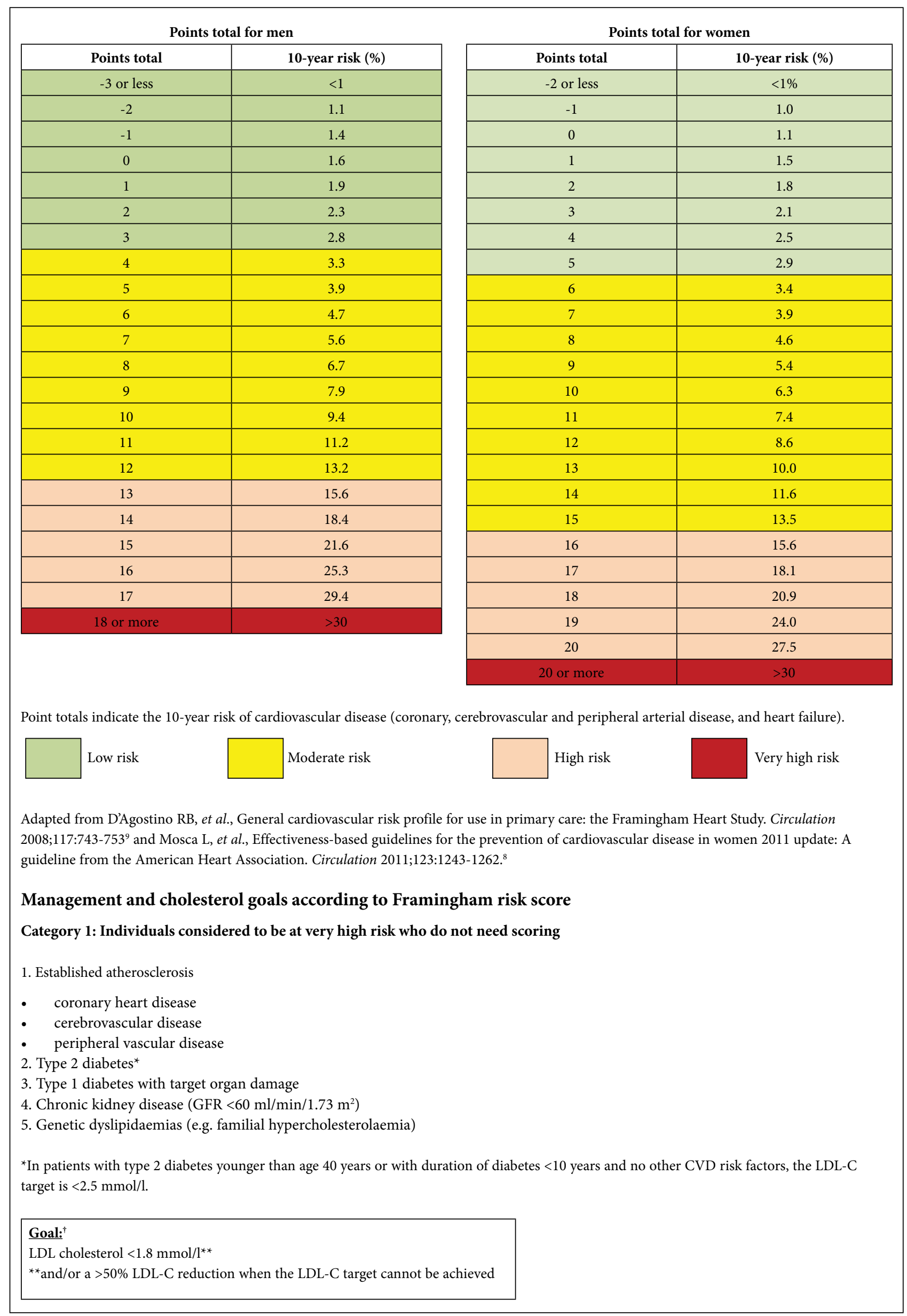




\section{Category 2: ${ }^{\ddagger}$ Risk scoring required - use the Framingham risk tables ${ }^{\S}$}

$\begin{array}{ll}\text { Use correct gender table: } & \text { Score: } \\ \text { 1. Age } & 1 . \\ \text { 2. Total cholesterol } & 2 . \\ \text { 3. Non-smoker/smoker } & 3 . \\ \text { 4. HDL-C } & 4 . \\ \text { 5. Systolic BP } & 5 .\end{array}$

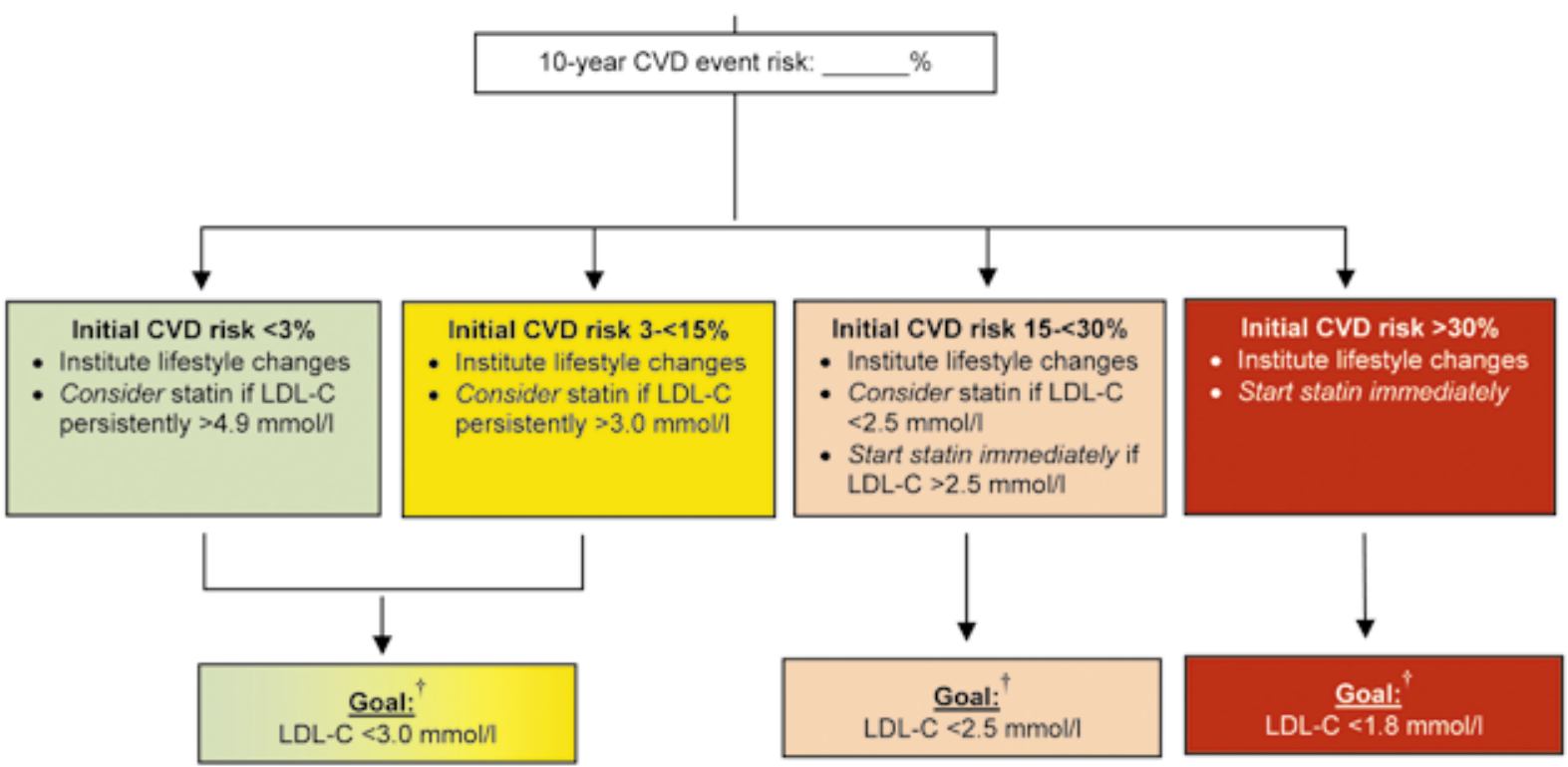

${ }^{\dagger}$ Pharmacological treatment is required if LDL cholesterol remains above these levels despite lifestyle modification. At present statins are first-line drugs for lowering LDL cholesterol.

*Secondary causes of dyslipidaemia should be excluded before progressing to risk assessment.

'See limitations of Framingham Risk Assessment Score on this page.

'Total cholesterol level is used to assign risk score and may be used for follow-up cholesterol measurement in patients on drug therapy, but LDL cholesterol is the target of treatment.

\section{Limitations of the Framingham Risk Assessment Score charts}

1. Patients who are classified in the very high-risk category do not require further risk scoring for management decisions. Risk will also be underestimated in patients who have a markedly elevated single risk factor (e.g. severe hypertension: systolic BP $>180 \mathrm{mmHg}$ and/or diastolic BP $>110 \mathrm{mmHg}$ ), or associated target organ damage.

2. Severe hypercholesterolaemia and hypertriglyceridaemia: The Framingham risk assessment chart is only accurate up to total cholesterol values of $7.25 \mathrm{mmol} / \mathrm{l}$ and cannot be used for patients with TC levels above this value. It also does not apply to hypertriglyceridaemia (triglyceride $>5$ $\mathrm{mmol} / \mathrm{l})$.

3. Family history of early atherosclerotic disease is not taken into account. Clinicians should use their judgement in deciding whether to place a patient with an impressive family history in the high-risk category regardless of their Framingham score.

4. Despite these factors being important risk factors for CVD, impaired glucose tolerance and abdominal obesity are not taken into account in the risk score.

LDL-C = low-density lipoprotein cholesterol; HDL-C = high-density lipoprotein cholesterol; $\mathrm{TG}=$ triglyceride; $\mathrm{CHD}=$ coronary heart disease; $\mathrm{CVD}=$ cardiovascular disease; $\mathrm{BP}=$ blood pressure.

\section{Conversion from $\mathrm{mg} / \mathrm{dl}$} Cholesterol:

$\mathrm{mmol} / \mathrm{l}=\mathrm{mg} / \mathrm{dl} \times 0.0259$

$\mathrm{mg} / \mathrm{dl}=\mathrm{mmol} / \mathrm{l} \times 38.6$

\section{Triglyceride:}

$\mathrm{mmol} / \mathrm{l}=\mathrm{mg} / \mathrm{dl} \times 0.0113$

$\mathrm{mg} / \mathrm{dl}=\mathrm{mmol} / \mathrm{l} \times 88.5$ 
Appendix 2. South African Heart Association/LASSA guidelines for lifestyle modification for patients with dyslipidaemia

1. Stop smoking and avoid exposure to environmental tobacco smoke.

2. Increase your physical activity. Try to do exercise of moderate intensity, such as brisk walking, for at least 30 minutes on all or most days of the week.

3. Achieve and maintain ideal body weight.

4. Reduce your intake of saturated fats, trans-fats and cholesterol. Avoid eating fatty meats, processed meats, chicken skin, processed meats, confectionery such as pies, pastries and cookies, fast foods, deep-fried potato chips ('slap chips'), butter, ghee, cream, hard cheeses and salty crackers.

5. Replace saturated fats with unsaturated fats. Avoid the use of hard margarines, butter and ghee for cooking or adding to food. Use unsaturated fats such as canola oil, olive oil and sunflower oil for cooking. Use oils sparingly and avoid all deep-frying of food. Remove all visible fat before cooking. Increase your intake of all types of fish, especially oily fish such as sardines and salmon, to a minimum of twice a week.

6. Increase your intake of fibre, especially soluble fibre. Include foods such as oats, fresh fruit and legumes (dry beans, soya beans, chickpeas, all types of lentils). Include a minimum of five portions of fresh fruit and vegetables in your daily diet.

7. Replace all refined carbohydrate types of foods with foods high in fibre, such as whole grains. Avoid eating products made from white flour, such as white bread and rolls, pizzas, vetkoek, samoosas, pies, prego rolls and bakery items such as cakes and biscuits. Incorporate wholegrain foods such as oats, barley, stampkoring (pearl wheat), crushed wheat, samp and beans, brown rice, brown/wild rice, whole-grain breakfast cereals, health and seed breads.

8. Avoid foods high in free sugars (sucrose, high-fructose corn syrup, fructose) such as sweets, chocolates, all fizzy soft drinks, fruit juices, all flavoured and sweetened waters, low-fat sweetened milky drinks.

9. If you consume alcohol, do so in moderation - no more than 2 drinks for men and 1 drink for women per day.

10. Avoid adding salt to food after cooking. Choose and prepare foods with little or no salt by using more herbs and spices.

11. For dietary lifestyle intervention all patients should ideally be referred to a registered dietician.

\section{$35^{\text {th }}$ National Congress of the South African Society of Obstetricians \& Gynaecologists (SASOG)}

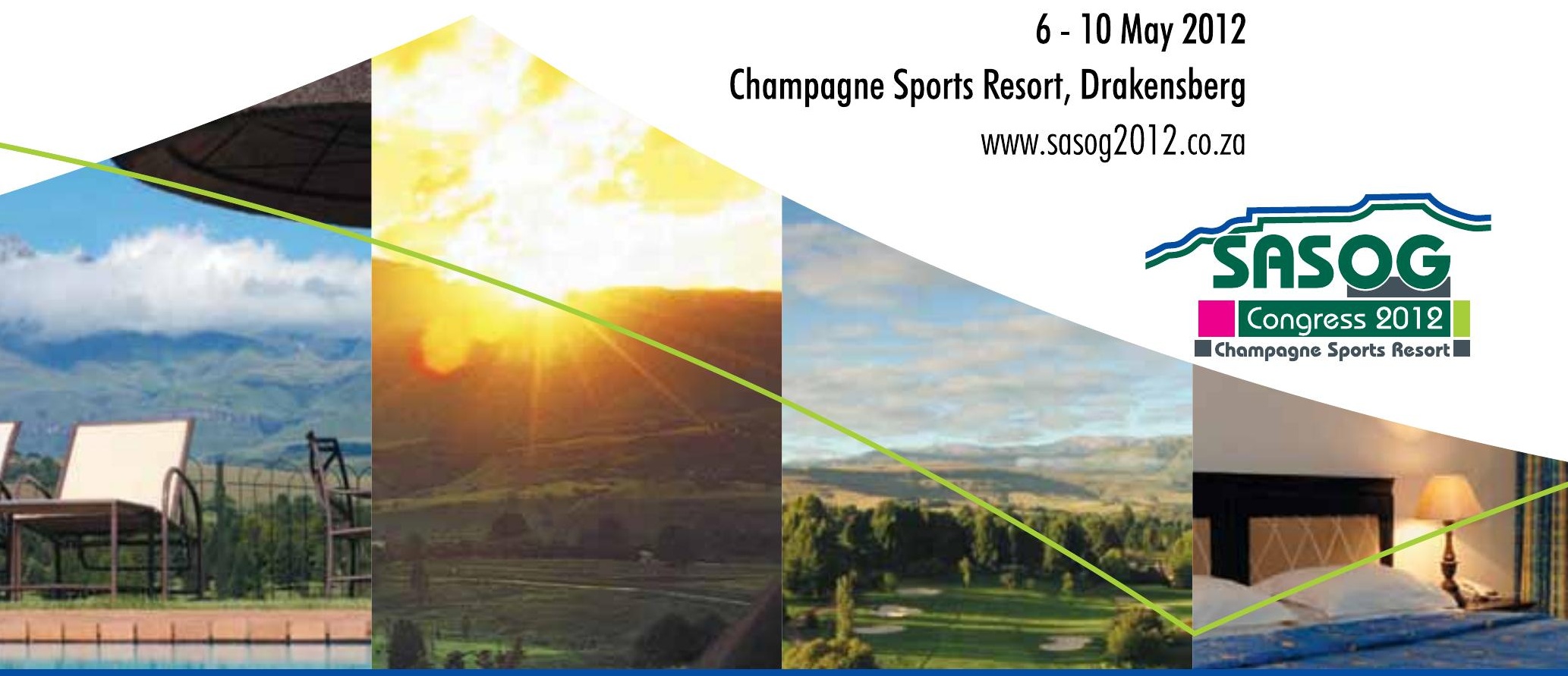

Enquiries: RK Communication - Rhyno Kriek

Tel: 0514367733 / $0832650265 • E-m a i l: ~ r k c @ t e l k o m s a . n e t$ 
